\title{
Non-clonal occurrence of $p m r B$ mutations associated with polymyxin resistance in carbapenem-resistant Klebsiella pneumoniae in Brazil
}

\author{
Ana Claudia Souza Rodrigues ${ }^{1,2}$, Ivson Cassiano de Oliveira Santos ${ }^{3}$, \\ Caroline Conci Campos ${ }^{4}$, Isadora Nascimento Rezende ${ }^{4}$, Yanara Miranda Ferreira ${ }^{4}$, \\ Claudia Elisabeth Volpe Chaves ${ }^{5}$, Cláudio Marcos Rocha-de-Souza ${ }^{3}$, \\ Ana Paula D'Alincourt Carvalho-Assef ${ }^{3}$, Marilene Rodrigues Chang ${ }^{1,4} /+$
}

\author{
${ }^{1}$ Universidade Federal de Mato Grosso do Sul, Faculdade de Medicina, Programa de Pós-Graduação em Saúde \\ e Desenvolvimento na Região Centro-Oeste, Campo Grande, MS, Brasil \\ ${ }^{2}$ Universidade Anhanguera Uniderp, Faculdade de Medicina, Campo Grande, MS, Brasil \\ ${ }^{3}$ Fundação Oswaldo Cruz-Fiocruz, Instituto Oswaldo Cruz, Laboratório de Pesquisa em Infecção Hospitalar, Rio de Janeiro, RJ, Brasil \\ ${ }^{4}$ Universidade Federal de Mato Grosso do Sul, Faculdade de Ciências Farmacêuticas, Alimentos e Nutrição, Campo Grande, MS, Brasil \\ ${ }^{5}$ Hospital Regional de Mato Grosso do Sul, Campo Grande, MS, Brasil
}

BACKGROUND Polymyxins are currently used as a "last-line" treatment for multidrug-resistant Gram-negative infections.

OBJECTIVES To identify the major mechanisms of resistance to polymyxin and compare the genetic similarity between multidrug resistant Klebsiella pneumoniae strains recovered from inpatients of public hospitals in the Mid-West of Brazil.

METHODS 97 carbapenems non-susceptible $K$. pneumoniae were studied. $\beta$-lactamases (bla $a_{\mathrm{OXA}-48}, b l a_{\mathrm{KPC}}, b l a_{\mathrm{NDM}}$, bla $a_{\mathrm{CTX}-\mathrm{M}}$, $\left.b l a_{\mathrm{SHV}}, b l a_{\mathrm{TEM}}, b l a_{\mathrm{IMP}}, b l a_{\mathrm{VIM}}\right)$ and $m c r-1$ to $m c r-5$ genes were investigated by polymerase chain reaction (PCR). Mutations in chromosomal genes ( $p m r A, p m r B$, phoP, phoQ, and $m g r B$ ) were screened by PCR and DNA sequencing. Clonal relatedness was established by using pulsed-field gel electrophoresis and multilocus sequence typing.

FINDINGS $K$. pneumoniae isolates harbored bla $a_{\mathrm{KPC}}(93.3 \%)$, bla $a_{\mathrm{SHV}}(86.6 \%)$, bla ${ }_{\mathrm{TEM}}(80.0 \%)$, bla $a_{\mathrm{CTX}-\mathrm{M}}(60 \%)$ genes. Of $15 \mathrm{~K}$. pneumoniae resistant to polymyxin B the authors identified deleterious mutations in $p m r B$ gene, mainly in T157P. None $K$. pneumoniae presented $\mathrm{mor}$ gene variants. Genetic polymorphism analyses revealed 12 different pulsotypes.

MAIN CONCLUSIONS Deleterious mutations in $p m r B$ gene is the main chromosomal target for induction of polymyxin resistance in carbapenem-resistant $K$. pneumoniae in public hospitals in the Mid-West of Brazil.

Key words: colistin - polymyxins - multidrug resistance

The emergence of carbapenem-resistant Klebsiella pneumoniae (CRKp) and the increased use of polymyxin $\mathrm{B}$ to treat infections caused by these microorganisms may have contributed to the spread of polymyxin-resistant $K$. pneumoniae isolates (PRKP). ${ }^{(1,2,3)}$ The polymyxin resistance is most commonly associated with the modification of the lipopolysaccharide (LPS) following the addition of 4-amino-4-deoxi-L-arabinose to lipid A. Modifications of Ara4N are regulated by two component systems: PhoP/ PhoQ, PmrA/PmrB and MgrB regulator. Mutations in genes involved in the production of these systems may result in lower antibiotic fixation. ${ }^{(4)}$ Previous studies reported that disruption of $m g r B$ gene is one of the major mechanisms of polymyxin resistance in K. pneumoniae. . $^{(2,5,6)}$

Recently, $m c r-1$ gene and its variants ( $m c r-1$ to $m c r-8$ genes) was described conferring resistance to polymyx-

\footnotetext{
doi: 10.1590/0074-02760180555

Financial support: CAPES, CNPq, FAPERJ, FIOCRUZ-RJ, UFMS,

+ Corresponding author: marirchang@yahoo.com.br

(1) https://orcid.org/0000-0003-3402-4740

Received 27 November 2018

Accepted 29 April 2019
}

in in Enterobacteriaceae isolated from humans, animals and environmental samples worldwide, including Brazil. $(7,8,9)$ The global dissemination of these genes may be a signal of a new era of pandrug resistant bacteria. ${ }^{(10)}$

To date, there is no information about the mechanisms of polymyxin resistance in Gram negative bacilli in Mato Grosso do Sul state. The aims of this study were to investigate the mechanisms of resistance to polymyxin and to evaluate the genetic diversity in carbapenem and polymyxin-resistant $K$. pneumoniae strains recovered from patients admitted in intensive care units of public hospitals in the Mid-West of Brazil.

\section{MATERIALS AND METHODS}

Bacterial isolates and susceptibility tests - A total of 97 carbapenem non-susceptible K. pneumoniae isolated from patients admitted in intensive care units of three tertiary hospitals in Mato Grosso do Sul, Brazil (Hospital A, 592 beds; Hospital B, 271 beds and Hospital C, 352 beds) between 2013 and 2014 were included in this study. The identification and antimicrobial susceptibility testing were performed by Vitek 2 compact System (bioMérieux, Marcy L'Etoile, France). The minimum inhibitory concentration (MIC) of tigecycline was determined by using E-test ${ }^{\circledR}$ strips (bioMérieux, Marcy L'Etoile, France) applied in Mueller-Hinton agar (Oxoid, England) according to the manufacturer's instructions. 
The polymyxin B MICs were performed by broth microdilution test according the CLSI ${ }^{(11)}$ Escherichia coli ATCC 25922 and Pseudomonas aeruginosa ATCC 27853 were used as quality control. BrCast ${ }^{\left({ }^{(2)}\right)}$ breakpoints were used for interpretation of tigecycline (Susceptible $\leq$ $1 \mathrm{mg} / \mathrm{L}$, Resistant $>2 \mathrm{mg} / \mathrm{L}$ ) and polymyxin MIC results (Susceptible $\leq 2 \mathrm{mg} / \mathrm{L}$, Resistant $>2 \mathrm{mg} / \mathrm{L}$ ). ${ }^{(12)}$ Multidrugresistance (MDR) was defined as non-susceptibility to at least one agent in three or more antimicrobial categories. Extensively drug-resistant (XDR) was defined as susceptible to only one or two categories in all. ${ }^{(13)}$

Screening for genes of resistance - Resistant genes $b l a_{\mathrm{OXA}-48^{-}{ }_{\text {like }},}$ bla ${ }_{\mathrm{KPC}}, b l a_{\mathrm{NDM}}$ were investigate by multiplex polymerase chain reaction (PCR) and $b l a_{\mathrm{CTX}-\mathrm{M}}$, bla $a_{\mathrm{SHV}}$, bla${ }_{\mathrm{TEM}}, b l a_{\mathrm{IMP}}, b l a_{\mathrm{VIM}}$ by simple PCR using primers as previously described..$^{(14,15,16,17)}$ The plasmid-mediated polymyxin resistance gene, $m c r-1$ to $m c r-5$, was determined by multiplex PCR using primers as previously described. ${ }^{(7)}$

Mutations in chromosomal genes ( $p m r A, p m r B$, phoP, phoQ, and $m g r B$ ) were screened by PCR and DNA sequencing. ${ }^{(18,19)}$ DNA was extracted from fresh bacterial colonies using an AxyPrep Bacterial Genomic DNA Miniprep kit (Axygen Scientific, Union city, CA, USA). The amplification products were purified using DNA Illustra GFX 96 kit (GE Healthcare Life Sciences, UK Ltd., Buckinghamshire, UK) and sequenced using the 3730 DNA analyser (Applied Biosystems, CA, USA). Data were analysed using Geneious (6.1.8) software (Auckland, New Zealand) and BLASTN (NCBI) tool (www.ncbi.nlm.nih.gov/blast). The PROVEAN platform was used to predict alterations in biological functions of proteins using K. pneumoniae MGH 78578 (CP00647.1) as reference.

Genotyping by pulsed-field gel electrophoresis (PFGE) and multilocus sequence typing (MLST) - Clonal relatedness among PRKp isolates was established using $X b a \mathrm{I}$ - PFGE (Promega, Charbonnières-les-Bains, France). DNA fragments were separated with a CHEF DR III apparatus (Bio-Rad; Richmond, CA - USA) and analysed by BioNumerics fingerprinting software (Applied Maths, Sint-Martens-Latem, Belgium). ${ }^{(20)}$

MLST was performed to subtype PRKp by amplification and sequenced of seven housekeeping genes (gapA, inf $B, m d h$, pgi, phoE, rpoB, and ton $B) .{ }^{(21)}$ The allelic profiles and sequence types (ST) were screened as determined by the Institute Pasteur Klebsiella MLST database (http://bigsdb.web.pasteur.fr/klebsiella/klebsiella.html).

Ethics - This study was approved by the Plataforma Brasil Research Ethics Committee.

\section{RESULTS}

Of the 97 carbapenem non-susceptible $K$. pneumoniae isolates studied, $15(15.5 \%)$ were resistant to polymyxin B $(\mathrm{MIC}>2 \mathrm{mg} / \mathrm{L}$ ) and nine of them had MIC $\geq 8 \mathrm{mg} / \mathrm{L}$. The PRKp isolates were recovered from culture of ten urines (66.7\%), two blood (13.3\%), two scar tissue (13.3\%) and one tracheal aspirate $(6.7 \%)$.

Antimicrobial susceptibility test showed that seven PRKp were XDR. The lower resistance antibiotics were amikacin (6.7\%), tigecycline (26.7\%) and fosfomycin
(33.3\%). All PRKp were resistant to carbapenems (including $13.3 \%$ with $\mathrm{MIC} \leq 8 \mu \mathrm{g} / \mathrm{mL}$ ) and cephalosporins. Screening resistance gene showed that PRKp isolates harbored $b l a_{\mathrm{SHV}}(86.6 \%)$, bla $_{\mathrm{TEM}}(80.0 \%)$, and bla $_{\mathrm{CTX}-\mathrm{M}}$ $(60 \%)$. Thirteen $K$. pneumoniae isolates contained three or more resistance genes and fourteen (93.3\%) PRKp isolates carried the $b l a_{\mathrm{KPC}}$ gene. The $b l a_{\mathrm{OXA} 48}, b l a_{\mathrm{NDM}}$, $b l a_{\mathrm{VIM}} \cdot b l a_{\mathrm{IMP}}$ and $m c r$ genes variants were not detected.

Ten PRKp isolates presented the same amino acid substitution from threonine to proline at position 157 (T157P) in PmrB protein and four of these contained another mutation (R256G) that is considered deleterious by PROVEAN software. Two PRKp isolates (A38 and S378) presented others non-neutral mutation (H58N, A66E, V67D, A66E, P272H, G318A) in PmrB. No mutations in the pmrA gene nor in the PhoP/PhoQ System were observed. K. pneumoniae isolates exhibited nonneutral mutation in $m g r B$ gene: A38B isolate with L19K mutation and S7 isolate with eight non-neutral mutation (V1G, K3V, L4P, W6S, V7D, L9K, I10N, V11K), including two insertions sequences. No mutation was associated with stop codon.

Genetic polymorphism analyses of PRKp revealed 12 different pulsotypes (A to L) by PFGE method with similarity below $85 \%$. MLST analysis showed 11 ST among these isolates. ST 11 (belonging to CC258) was present in four PRKp isolates of all hospitals studied and ST13 in three PRKp, from two hospitals (A and C). The antimicrobial susceptibility profiles, resistance genes determinants and clonal patterns are shown in Table.

\section{DISCUSSION}

Infections caused by multidrug-resistant $K$. pneumoniae are currently a concern in public health. Polymyxins are often the last line of therapeutic options for the treatment. Consequently, a high mortality rate has been observed, especially in intensive therapy units. ${ }^{(22)}$

It is well documented in the literature that the levels of resistance to antibiotics may vary according to the hospital characteristics and distinct geographic areas. In our study, PRKp isolates showed low resistance to tigecycline, fosfomycin, and amikacin suggesting these antibiotics would be successful as treatments in infections caused by carbapenem and polymyxin-resistant $K$. pneumoniae.

The results of this study show different mechanisms of antimicrobial resistance, including non-neutral mutations in $p m r B$ gene (A66E, P272H, G318A, H58N, V67D) not previously associated to polymyxin resistance in K. pneumoniae.

Similar to previous Brazilian studies, ${ }^{(1,2,23)}$ we also observed a high rate KPC-producing K. pneumoniae and described high genetic diversity among the isolates.

Almost $50 \%$ of K. pneumoniae studied was considered $K$. pneumoniae XDR. The high resistance to $\beta$-lactams observed (Table) may be related to the presence of genes as $b l a_{\mathrm{SHY}}, b l a_{\mathrm{TEM}}$ and $b l a_{\mathrm{CTX}-\mathrm{M}}$, mainly $b l a_{\mathrm{KPC}}$.

Recent Brazilian studies carried out in the Southeast region of Brazil demonstrate a temporal increase of resistance to polymyxin since 2009 , ranging from 0 to $30.6 \%{ }^{(2,3,24)}$ In our study, we documented that $15.5 \%$ of K. pneumoniae isolated between 2013 and 2014 were resistant to polymyxin, in the Brazilian Mid-West hos- 


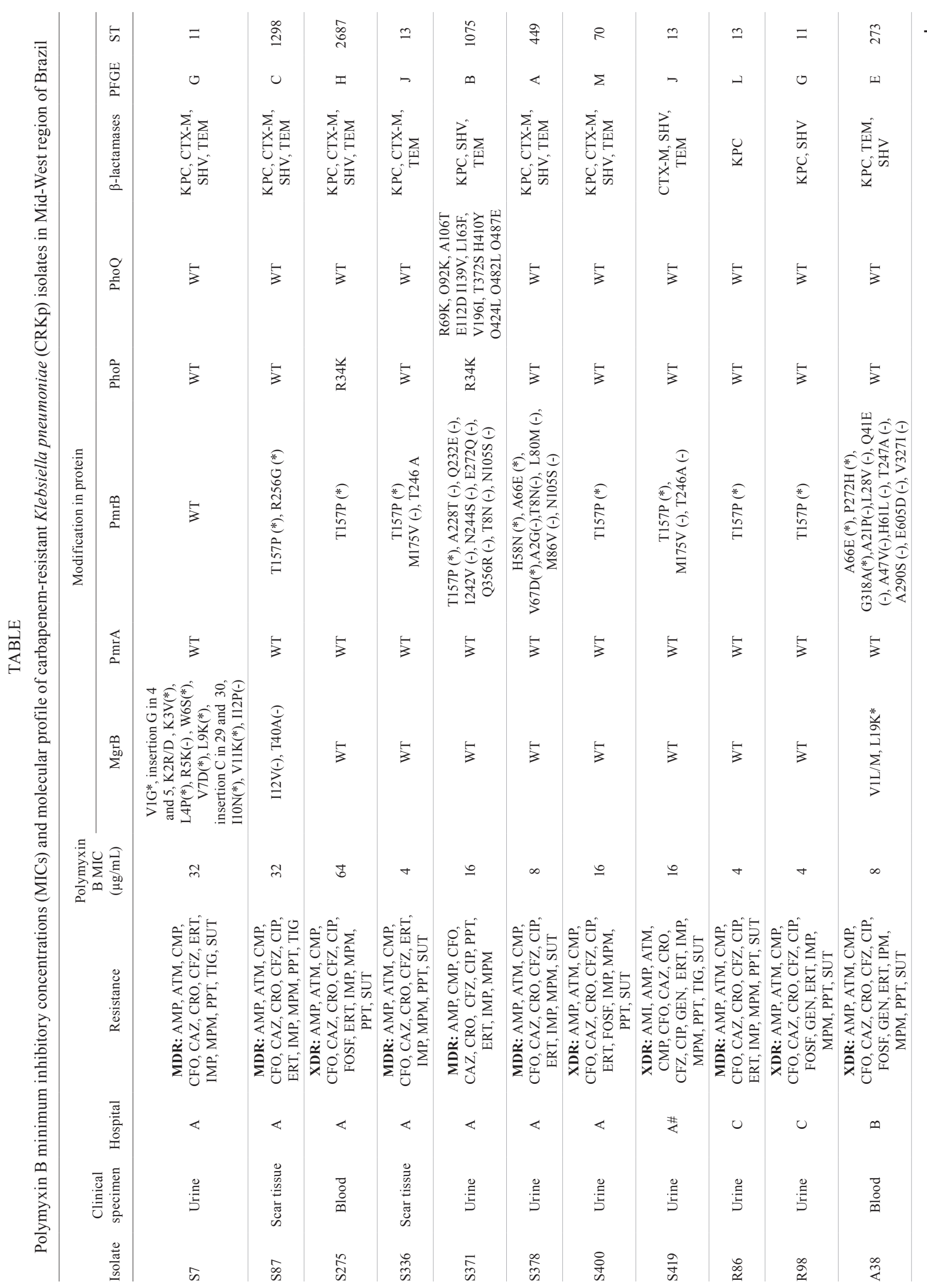




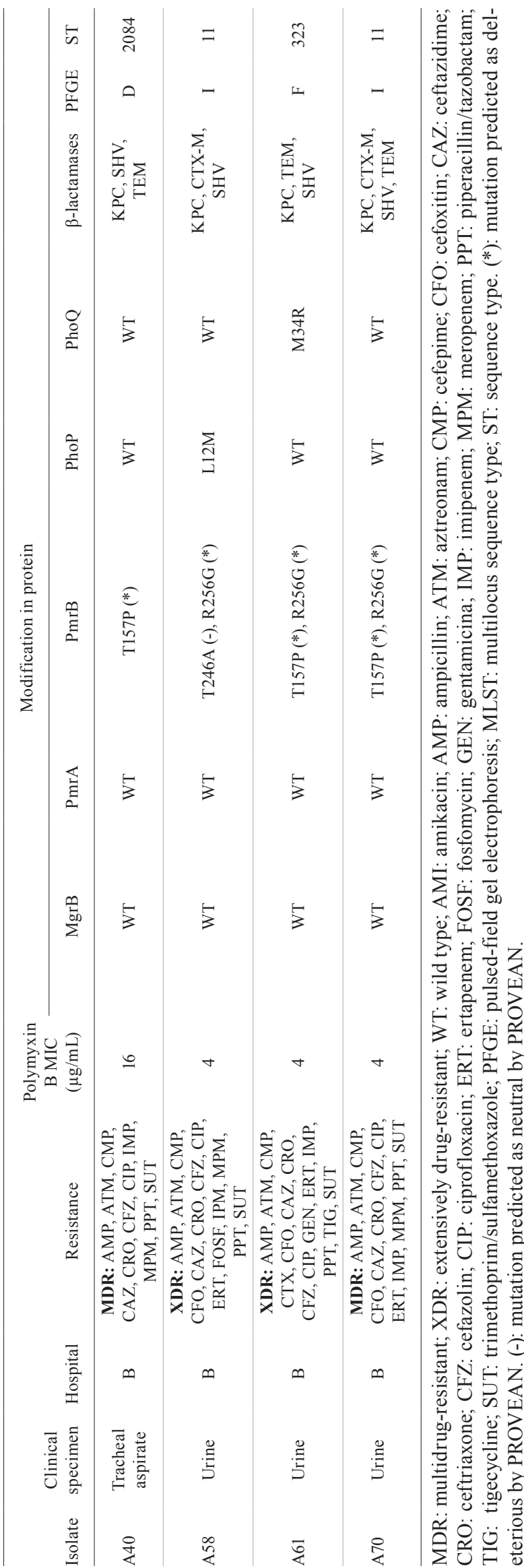

pitals. This is the first description of resistance to polymyxin in this region.

The genetic analysis demonstrates that in these hospitals the resistance to polymyxin are from chromosomal origin because none K. pneumoniae presented $\mathrm{mcr}$ gene variants.

Although previous studies report that alterations in the $m g r B$ gene is the main mechanisms of polymyxin resistance in Brazil and worldwide, ${ }^{(2,5,6,25,26)}$ in our study, only two PRKp presented deleterious mutations in this gene. Aires et al. ${ }^{(6)}$ reported disruption in $m g r B$ gene by IS903B, IS5, IS102, ISKpn 26 (IS5 family), and IS10L (IS4 family) in different regions of Brazil, including two K. pneumoniae from the Mid-West region (Distrito Federal).

Different from what was expected the majority of PRKp isolates studied carried alterations in $p m r B$ gene, mainly in T157P. To be best of our knowledge, this kind of alteration has not been described in Brazil prior to this study. Jayol et al. ${ }^{(19)}$ showed this point mutation in the $p m r B$ gene (T157P) leads to an upregulation to $\mathrm{pm}$ rCAB and pmrHFIJKLM operons conferring resistance to polymyxins in $K$. pneumoniae isolates from SouthAfrica, Colombia and Turkey. ${ }^{(19)}$

In our study, we identified four PRKp with non-neutral mutation (R256G) on PmrB protein as also described by Aires et al. ${ }^{(6)}$ in the Southeast region of Brazil ${ }^{(6)}$ Pitt et al. ${ }^{(26)}$ detected $\mathrm{R} 256 \mathrm{G}$ in polymyxin-susceptible and in polymyxin-resistant $K$. pneumoniae, suggesting that this mutation is not determinant for polymyxin resistance. The same authors related simultaneous alterations in $p m r \mathrm{~B}(\mathrm{P} 158 \mathrm{R}, \mathrm{T} 140 \mathrm{P})$ and in $m g r \mathrm{~B}$ genes with increases the MIC values.

In the hospitals studied, no relationship was observed between MIC values and mutations in $p m r B$ genes. However, in K. pneumoniae with mutations in $\operatorname{mgrB}$ gene we observed high level polymyxin-resistant (MIC $=32 \mu \mathrm{g}$ / $\mathrm{mL}$ ), as also described by Aires et al. ${ }^{(6)}$

The most prevalent mechanism of resistance to polymyxin observed in the Mid-West region is due to mutation in the $p m r B$ gene, different from that observed (mutation in the $m g r \mathrm{~B}$ gene) in other Brazilian states. ${ }^{(1,2,6)}$ Antimicrobial pressures may be responsible for the evolution of different mutation profiles observed between different geographic regions.

Our study reveals high clonal diversity among PRKp isolates including nine different ST's (ST13, ST70, ST273, ST449, ST323, ST2084, ST1075, ST1298, ST2687) that were not associated to polymyxin resistance previously. ST11 (CC258) was the most prevalent sequence type, followed by ST13. ST11 clone has been detected worldwide as the main international high-risk clones of $K$. pneumoniae associated with outbreaks and dissemination of carbapenemases and polymyxin resistance. ${ }^{(1,2,4,6,27)}$ Braun et al. ${ }^{(2)}$ described ST258 and ST437 (both belonging to 258 clonal complex) as the main sequence types in PRKp isolated from São Paulo, Brazil.

The emergence and evolution of complex 258 in KPC-K. pneumoniae is carried by mobile transposable elements. Pereira et al. ${ }^{(1)}$ described the clonal diversity in Brazil with prevalence of ST11 and ST340 in Northeast region, ST437 in South and Southeast regions and ST11 in Mid-West. 
Our results suggest that PRKp isolates belonging to ST11 and ST13 clones are adapted in Mid-West region and highlights the emergence of new ST in PRKp (ST70, ST273, ST449, ST323, ST2084, ST1075, ST1298, ST2687). Complementation assays should be done later to elucidate the role of these STs and polymyxin resistance.

In conclusion - Our results show that many K. pneumoniae not susceptible to carbapenem isolated in Brazilian Mid-West Hospitals are considered MDR and XDR, but still show low resistance to tigecycline, fosfomycin and amikacin. The high resistance to $\beta$-lactams observed may be related to the presence of genes as $b l a_{\mathrm{SHV}}, b l a_{\mathrm{TEM}}$ and $b l a_{\text {CTX-M }}$, mainly $b l a_{\mathrm{KPC}}$.

The resistance to polymyxin are from chromosomal origin because none K. pneumoniae presented $\mathrm{mcr}$ gene variants. The main mechanism of resistance to polymyxin in K. pneumoniae in the hospitals studied is due to a mutation in the $\operatorname{pmr} B$ gene.

\section{ACKNOWLEDGEMENTS}

To the team of the Microbiology laboratories of the Hospitals for providing the Klebsiella pneumoniae studied.

\section{AUTHORS' CONTRIBUTION}

APDC-A and MRC conceived and designed the study and review the results and the manuscript; CCC, INR and YMF were responsible for samples collection, strain isolation and identification, ACSR and ICOS conducted the experiments of PFGE, antimicrobial assays and PCR; ICOS sequenced the genome; MRC, CEVC and CMR-de-S contributed for the manuscript writing.

\section{REFERENCES}

1. Pereira PS, De Araujo CF, Seki LM, Zahner V, Carvalho-Assef AP, Asensi MD. Update of the molecular epidemiology of KPC-2-producing Klebsiella pneumoniae in Brazil: spread of clonal complex 11 (ST11, ST437 and ST340). J Antimicrob Chemother. 2013; 68(2): 312-16.

2. Braun G, Cayo R, Matos AP, Fonseca JM, Gales AC. Temporal evolution of polymyxin B-resistant Klebsiella pneumoniae clones recovered from blood cultures in a teaching hospital during a 7-year period. Int J Antimicrob Agents. 2018; 51(3): 522-27.

3. Rossi F, Girardello R, Cury AP, Di Gioia TS, Almeida Jr JN, Duarte AJ. Emergence of colistin resistance in the largest university hospital complex of São Paulo, Brazil, over five years. Braz J Infect Dis. 2017; 21(1): 98-101.

4. Poirel L, Jayol A, Nordmann P. Polymyxins: antibacterial activity, susceptibility testing, and resistance mechanisms encoded by plasmids or chromosomes. Clin Microb Reviews. 2017; 30(2): 557-96.

5. Poirel L, Jayol A, Bontron S, Villegas MV, Ozdamar M, Türkoglu $\mathrm{S}$, et al. The $m g r B$ gene as a key target for acquired resistance to colistin in Klebsiella pneumoniae. J Antimicrob Chemother. 2014; 70(1): 75-80.

6. Aires CA, Pereira PS, Asensi MD, Carvalho-Assef AP. $M g r B \mathrm{Mu}-$ tations mediating polymyxin B resistance in Klebsiella pneumoniae isolates from rectal Surveillance Swabs in Brazil. Antimicrob Agents Chemother. 2016; 60(11): 6969-72.

7. Rebelo AR, Bortolaia V, Kjeldgaard JS, Pedersen SK, Leekitcharoenphon P, Hansen IM, et al. Multiplex PCR for detection of plasmid-mediated colistin resistance determinants, $\mathrm{mcr}$ - $1, \mathrm{mcr}$-2, $\mathrm{mcr}$ $3, m c r-4$ and $m c r-5$ for surveillance purposes. Euro Surveill. 2018; 23(6). doi: doi.org/10.2807/1560-7917.
8. Wang X, Wang Y, Zhou Y, Li J, Yin W, Wang S, et al. Emergence of a novel mobile colistin resistance gene, $m c r-8$, in NDM-producing Klebsiella pneumoniae. Emerg Microbes Infect. 2018; 7(1): 122.

9. Fernandes MR, McCulloch JA, Vianello MA, Moura Q, PérezChaparro PJ, Esposito F, et al. First report of the globally disseminated IncX4 plasmid carrying the $m c r-1$ gene in a colistin-resistant Escherichia coli sequence type 101 isolate from a human infection in Brazil. Antimicrob Agents Chemother. 2016; 60(10): 6415-17.

10. Srijan A, Margulieux KR, Ruekit S, Snesrud E, Maybank R, Serichantalergs $\mathrm{O}$, et al. Genomic characterization of nonclonal $\mathrm{mcr}-1$ positive multidrug-resistant Klebsiella pneumoniae from clinical samples in Thailand. Microb Drug Resist. 2018; 24(4): 403-10.

11. CLSI - Clinical and Laboratory Standards Institute. Performance standards for antimicrobial susceptibility testing 22th informational supplement (M100-S27) 2017. Wayne: CLSI; 2017.

12. BrCast. Comitê brasileiro de avaliação de suscetibilidade antimicrobiana 2017. Available from: brcast.org.br/documentos/.

13. Magiorakos AP, Srinivasan A, Carey RB, Carmeli Y, Falagas ME, Giske CG, et al. Multidrug-resistant, extensively drug-resistant and pandrug-resistant bacteria: an international expert proposal for interim standard definitions for acquired resistance. Clin Microbiol Infect. 2012; 18(3): 268-81.

14. Mulvey MR, Soule G, Boyd D, Demczuk W, Ahmed R. Characterization of the first extended-spectrum $\beta$-lactamases-producing Salmonella isolate identified in Canada. J Clin Microbiol. 2003; 41(1): 460-2.

15. Hasman H, Mevius D, Veldman K, Olesen I, Aarestrup FM. B-lactamasess among extended-spectrum $\beta$-lactamases (ESBL)-resistant Salmonella from poultry, poultry products and human patients in The Netherlands. J Antimicrob Chemother. 2005; 56(1): 115-21.

16. Monteiro J, Widen RH, Pignatari AC, Kubasek C, Silbert S. Rapid detection of carbapenemase genes by multiplex real-time PCR. J Antimicrob Chemother. 2012; 67(4): 906-9.

17. Senda K, Arakawa Y, Ichiyama S, Nakashima K, Ito H, Ohsuka $\mathrm{S}$, et al. PCR detection of metallo- $\beta$-lactamases gene (blaIMP) in gram-negative rods resistant to broad-spectrum beta-lactams. J Clin Microbiol. 1996; 34(12): 2909-13.

18. Cannatelli A, D’Andrea MM, Giani T, Di Pilato V, Arena F, Ambretti S, et al. In vivo emergence of colistin resistance in Klebsiella pneumoniae producing KPC-type carbapenemases mediated by insertional inactivation of the $\mathrm{PhoQ} / \mathrm{PhoP}$ mgrB regulator. Antimicrob Agents Chemother. 2013; 57(11): 5521-6.

19. Jayol A, Poirel L, Brink A, Villegas MV, Yilmaz M, Nordmann P. Resistance to colistin associated with a single amino acid change in protein PmrB among Klebsiella pneumoniae isolates of worldwide origin. Antimicrob Agents Chemother. 2014; 58(8): 4762-6.

20. Ribot EM, Fair MA, Gautom R, Cameron DN, Hunter SB, Swaminathan B, et al. Standardization of pulsed-field gel electrophoresis protocols for the subtyping of Escherichia coli O157:H7, Salmonella, and Shigella for PulseNet. Foodborne Pathog Dis. 2006; 3(1): 59-67.

21. Diancourt L, Passet V, Verhoef J, Grimont PA, Brisse S. Multilocus sequence typing of Klebsiella pneumoniae nosocomial isolates. J Clin Microbiol. 2005; 43(8): 4178-82.

22. Richter SE, Miller L, Uslan DZ, Bell D, Watson K, Humphries $\mathrm{R}$, et al. Risk factors for colistin resistance among gram-negative rods and Klebsiella pneumoniae isolates. J Clin Microbiol. 2018; 56(9): 149-218.

23. Biberg CA, Rodrigues AC, do Carmo SF, Chaves CE, Gales AC, Chang MR. KPC-2-producing Klebsiella pneumoniae in a hospital in the Mid-West region of Brazil. Braz J Microbiol. 2015; 46(2): 501-4. 
24. Bartolleti F, Seco BM, Dos Santos CC, Felipe CB, Lemo MEB, Alves TS, et al. Polymyxin B resistance in carbapenem-resistant Klebsiella pneumoniae, São Paulo, Brazil. Emerg Infect Dis. 2016; 22(10): 1849-51.

25. Huichuan Z, Dongdong Z, Qiucheng S, Jingjing Q, Xi L, Yunsong Y. The $m c r-1$ gene has no effect on colistin resistance when it coexists with inactivated $m g r b$ gene in Klebsiella pneumoniae. Microb Drug Res. 2018; 24(8): 1117-20.
26. Pitt ME, Elliott AG, Cao MD, Ganesamoorthy D, Karaiskos I, Giamarellou $\mathrm{H}$, et al. Multifactorial chromosomal variants regulate polymyxin resistance in extensively drug-resistant Klebsiella pneumoniae. Microb Genom. 2018; 4(3): 158. doi.org/10.1099/mgen.0.000158.

27. Andrade LN, Vitali L, Gaspar GG, Bellissimo-Rodrigues F, Martinez R, Darini AL. Expansion and evolution of a virulent, extensively drug-resistant (polymyxin B-resistant), QnrS1-, CTX-M-2-, and KPC-2-producing Klebsiella pneumoniae ST11 international high-risk clone. J Clin Microbiol. 2014; 52(7): 2530-5. 